\title{
ROLE OF LARGE-SCALE COHERENT STRUCTURES IN IMPINGING JET HEAT TRANSFER
}

\author{
KUNIO KATAOKA, RYUICHI SAHARA, HISASHI ASE \\ AND TAKAO HARADA \\ Department of Chemical Engineering, Kobe University, Kobe 657
}

Key Words: Convective Heat Transfer, Coherent Structure, Large Scale Eddy, Impinging Jet, Stagnation Point, Conditional Sampling, Turbulent Flow, Augmentation

\begin{abstract}
A large-scale coherent structure responsible for the enhancement of stagnation-point heat transfer was successfully determined using a statistical analysis with conditional sampling in an impinging round jet. It was found that the optimal nozzle-to-plate spacing for maximal stagnation-point heat transfer is identical with the jet development length for a strong turbulent stream carrying large-scale energy-containing eddies. A physical model of heat transfer enhancement was experimentally derived from the viewpoint of turbulent surface-renewal induced by large-scale eddies impinging on the stagnation-point boundary layer. It was found that the effect of heat transfer enhancement is a function of the proposed surface-renewal parameter consisting of the characteristic turbulence intensity and frequency of the large-scale eddies.
\end{abstract}

\section{Introduction}

One of the most promising flow systems for heat transfer augmentation is a turbulent jet impinging on a heat transfer surface. ${ }^{10)}$ As distinct from parallel flows along a solid wall, a free jet can easily attain very high intensities of turbulence in the process of jet development by virtue of large-scale eddies. How far a heat transfer surface should be placed away from a jet exit is therefore a very important question.

This paper deals with convective heat transfer in a turbulent, round air jet impinging normally on a large flat plate. According to previous work ${ }^{9,17)}$ regarding high-temperature, variable-density jets, a flat plate should be placed at the end of the potential core region in order to attain maximal heat fluxes at the stagnation point. For the case of isothermal free jets issuing from a well-shaped convergent nozzle, the optimal nozzle-to-plate spacing usually lies between six and eight nozzle diameters. ${ }^{4,5,7,13,16)}$

The effect of turbulence on heat transfer in the stagnation-point region has been studied by many investigators. ${ }^{1,2,5,7,13)}$ The effect of enhancement can generally be expressed by the so-called turbulence correction factor:

$$
\frac{N u}{R e^{1 / 2}}=(1+\varepsilon)\left(\frac{N u}{R e^{1 / 2}}\right)_{T F}
$$

In a manner similar to the case of heat transfer from circular cylinders, ${ }^{15)} \varepsilon$ can be regarded as a function of $T u \sqrt{R e}$ for the stagnation-point heat

\footnotetext{
Received June 5, 1986. Correspondence concerning this article should be addressed to K. Kataoka.
}

transfer..$^{5,7)}$

A phenomenological approach advanced by Gorla and $\mathrm{Nemeth}^{6)}$ introduces the eddy diffusivity induced by free stream turbulence intensity and integral length scale for the case of circular cylinders in crossflow. However, the mechanism for the heat transfer enhancement in impinging jets is different in that turbulent structures of much larger scale should be taken into account in the approaching stream. ${ }^{11,19)}$ The objective of the present work is to establish a physical model by observation of large-scale coherent structure in impinging jets. The research is focused on the stagnation-point region.

\section{Experimental}

Figure 1 shows the experimental setup. An isothermal air jet, issuing vertically upward from a smoothlycurved orifice-type convergent nozzle $(d=40 \mathrm{~mm})$, impinges normally on a horizontal, circular flat plate. The jet exit has a uniform velocity distribution with low initial turbulence $(<0.5 \%)$.

Details of the circular flat plate are shown in Fig. 2. The circular flat plate made of copper was $420 \mathrm{~mm}$ in diameter and $10 \mathrm{~mm}$ thick. A hot water jacket was installed on the back side of the flat plate so as to keep it at a constant uniform temperature (usually at $\left.52^{\circ} \mathrm{C}\right)$.

Local heat flux on the surface of the flat plate was measured by means of a Gardon-type heat-flux sensor $^{3)}$ shown in Fig. 3. The sensor consisted of a copper hollow male-screw as a heat sink and a circular constantan foil ( $14 \mu \mathrm{m}$ thick) which had a spot-welded thermocouple junction of $50 \mu \mathrm{m}$ dia. copper lead at its 


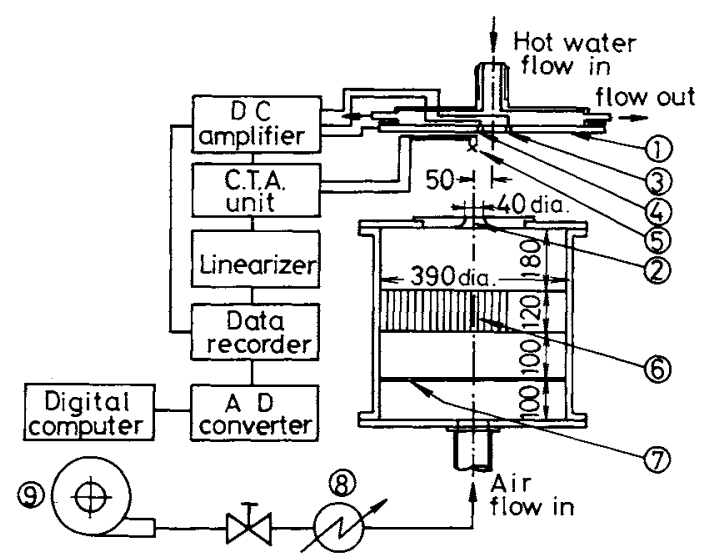

Fig. 1. Schematic of experimental setup. Dimensions in mm. 1, circular flat plate; 2 , bellmouth orifice-type convergent nozzle; 3, Gardon heat-flux sensor; 4, copper plug heat-flux gauge; 5, X-probe; 6, straw-tube calming section; 7 , perforated plate; 8 , heat exchanger; 9 , blower

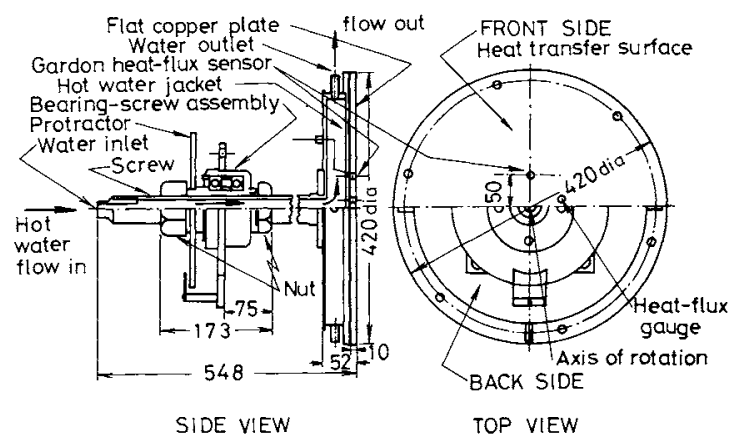

Fig. 2. Circular flat plate. Dimensions in $\mathrm{mm}$.

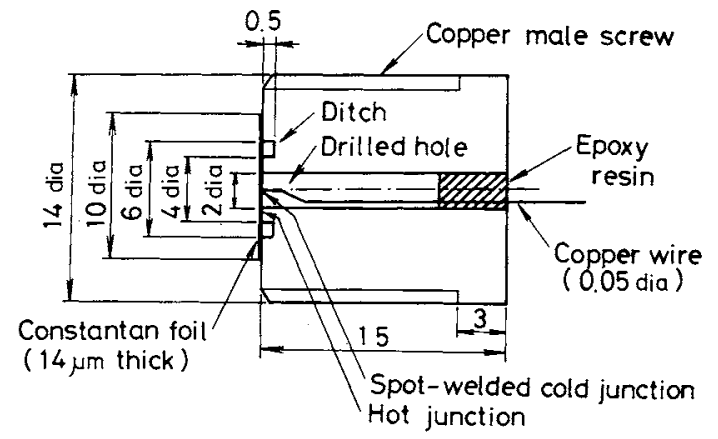

Fig. 3. Gardon-type heat-flux sensor. Dimensions in $\mathrm{mm}$.

center. The other thermocouple junction was formed at the periphery of the constantan foil. The sensor was embedded in the flat plate, $50 \mathrm{~mm}$ from the rotation axis.

The local heat transfer coefficient was calculated from the temperature difference between those two junctions. Another type of copper plug heat-flux gauge, ${ }^{9)}$ embedded in the same flat plate, was used to measure wall temperature directly. The axis of the convergent nozzle was fixed $50 \mathrm{~mm}$ away from the rotation axis of the flat plate so that the heat-flux sensor could be placed at an arbitrary radial position $r$ from the geometrical stagnation point $(r=0)$ by turning the flat plate. The turbulent velocities of the air jet measured by a constant-temperature $\mathrm{X}$-probe were analyzed by a statistical method with conditional sampling. ${ }^{12,14,18)}$ The interval of sampling was $1 \mathrm{~ms}$. The number of digitized velocity data was about 20,000 .

\section{Experimental Results}

Figure 4 shows the axial development of free jets measured by means of the X-probe. It can be seen from the figure that the potential core region covers 4.5 nozzle diameters, i.e. $z / D=4.5$, and that the turbulence intensity of the centerline velocity becomes maximal at about $z / D=7$.

Figure 5 shows the measured stagnation-point heat transfer coefficients in the form of the Frössling number based on the nozzle exit velocity and diameter. It is found that they become maximal in the limited range of nozzle-to-plate spacing $H / D=5-8$, as expected from the literature.e.g.7,8,13) The optimal nozzle-to-plate spacing for the maximal coefficient tends to move slightly from 5 toward 8 , with increasing $R e_{o}$ within the experimental condition. That is due to a slight increase in the length of potential core with increasing $R_{e}$.

It can be seen from Fig. 4 that the axial position $(z / D \fallingdotseq 4)$ where the centerline velocity $U_{m}$ of free jets begins to decrease essentially from its initial value $U_{o}$ does not coincide with the axial position $(z / D \fallingdotseq 6-7)$ where its turbulence intensity $\sqrt{{\overline{u_{m}}}^{2}}$ attains maximal value. Judging from Figs. 4 and 5 , it can be considered that a flat plate as the heat transfer surface should be placed at the latter position rather than at the former in order to attain the maximal coefficient of stagnation-point heat transfer.

\section{Discussion}

The theoretical value of the stagnation-point heat transfer coefficient for the turbulence-free condition, using the axisymmetric Hiemenz flow approximation, is of the form ${ }^{9)}$

$$
\left(\frac{N u}{\operatorname{Re}_{s}^{1 / 2} \operatorname{Pr}^{1 / 2}}\right)_{T F}=0.88 \quad \operatorname{Pr} \leq 1
$$

Donaldson et al. $^{2)}$ derived a similar laminar solution with a numerical constant 1.06 in place of 0.88 .

Hoogendoorn ${ }^{7)}$ tried to correlate his stagnationpoint heat transfer data in a functional form similar to that found for circular cylinders ${ }^{15}$ in a uniform turbulent air stream. Hoogendoorn's original expression was rewritten, dividing through by $\mathrm{Pr}^{1 / 2}$ under the assumption of $\operatorname{Pr}=0.7$ for air to obtain the correlation equation in the following form: 


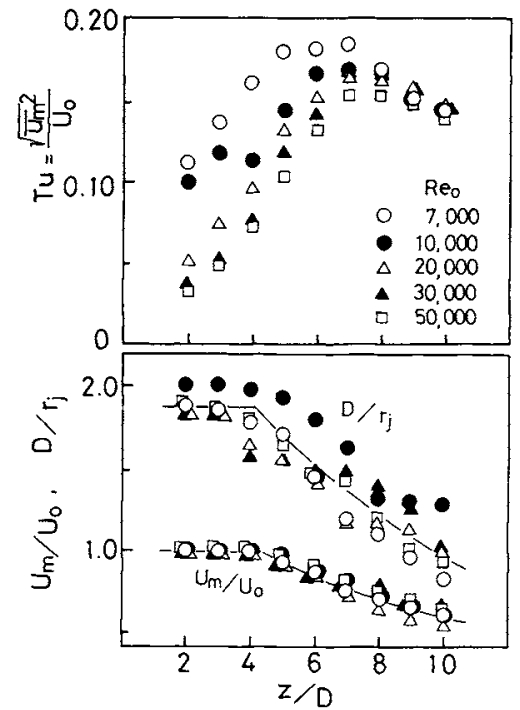

Fig. 4. Axial development of free jets.

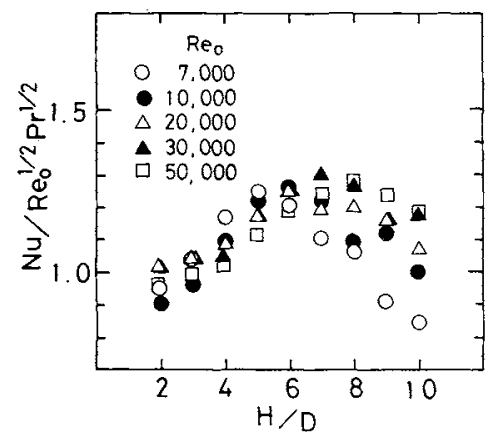

Fig. 5. Variation of stagnation-point heat transfer with nozzle-to-plate spacing.

$$
\begin{aligned}
& \frac{N u}{R e_{m}^{1 / 2} \operatorname{Pr}^{1 / 2}} \\
& \quad=0.78+2.43\left(\frac{T u_{m} \sqrt{R e_{m}}}{100}\right)-2.94\left(\frac{T u_{m} \sqrt{R e_{m}}}{100}\right)^{2}
\end{aligned}
$$

In a way similar to that of Hoogendoorn, ${ }^{7}$ the Frössling numbers observed in the present work were well correlated with the same turbulence intensity parameter $T u_{m} \sqrt{R e_{m}}$, as shown in Fig. 6. The best-fit equation is

$$
\begin{aligned}
& \frac{N u}{R e_{m}^{1 / 2} \operatorname{Pr}^{1 / 2}} \\
& \quad=0.82+2.83\left(\frac{T u_{m} \sqrt{R e_{m}}}{100}\right)-2.30\left(\frac{T u_{m} \sqrt{R e_{m}}}{100}\right)^{2}
\end{aligned}
$$

The present observations for large $T u_{m} \sqrt{R e_{m}}$ give Frössling numbers about $20 \%$ higher than Hoogendoorn's correlation curve. Nevertheless, these deviations are not surprising judging from the difficulty in heat transfer measurement and the difference in shape and size of the nozzles used. These cor-

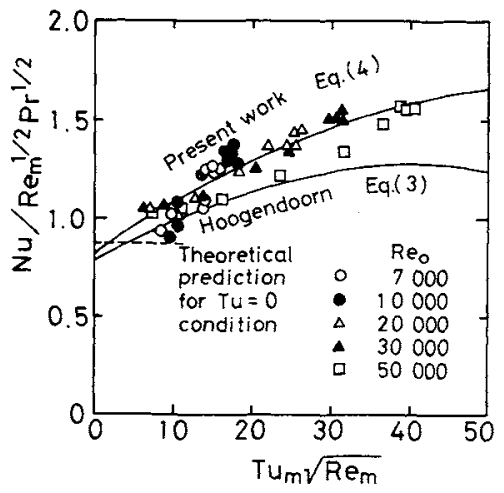

Fig. 6. Correlation of stagnation-point heat transfer with turbulence intensity parameter. The Hoogendoorn curve was obtained by dividing through his original correlation equation by $\operatorname{Pr}^{1 / 2}$ under the assumption of $P r=0.7$ for air for comparison with the present observations.

relation equations are of practical use because $T u_{m} \sqrt{R e_{m}}$ can easily be specified, using the experimental data of free jet development available in the literature.

As mentioned above, Hoogendoorn ${ }^{7)}$ adopted the free jet flow conditions that would exist at the plane of impingement in the absence of the flat plate. This approach, however, while practically useful for correlating data over a wide range of $H / D$, does not account for the characteristics of the impingement flowfield and, therefore, provides little basic idea for further phenomenological study of the mechanism for heat transfer enhancement.

As distinct from the stagnant heat transfer from cylinders in uniform crossflow, the question of where the turbulence intensity parameter should be defined is very important. As pointed out by Giralt et al., ${ }^{5)}$ the turbulence intensity parameter may be specified at the beginning of the impingement region. That point is located at about $1.2 D$ for $H / D \leq 6.8$ and $0.153(D+H)$ for $H / D>6.8$ from the stagnation point. However, that position is too far from the outer edge of the stagnation-point boundary layer to study the effect of free-stream turbulence on the impingement heat transfer because the boundary layer thickness is of the order of $0.02 \mathrm{D}$ for $R e=10,000$ according to the laminar solution, Eq. (3), of the previous paper. ${ }^{9)} \mathrm{At}$. the present stage, it is difficult to give a definite position for the definition of free-stream turbulence.

In the present work, a fixed point on the jet axis $0.3 \mathrm{D}$ upstream of the stagnation point is adopted as the defining position. Because the integral length scale is nearly equal to the width of the jet mixing layer (i.e. the jet half-radius), the distance $0.3 D$ can be interpreted as the nearest approach distance to the flat plate of the large-scale eddies impinging on the stagnation-point boundary layer for nozzle-to-plate spacings $H / D=5 \sim 8$.

The integral time scale was calculated from the 
autocorrelation of the arrival velocity fluctuations measured at that position:

$$
\begin{gathered}
R(\tau)=\frac{\overline{u_{s}(t) \overline{u_{s}(t+\tau)}}}{\overline{u_{s}^{2}}} \\
T=\int_{0}^{\infty} R(\tau) d \tau
\end{gathered}
$$

This integral time scale was adopted as the characteristic time scale of the fully turbulent jet region.

However the potential core region $(H / D \leq 4.5)$ is not fully turbulent but has periodical velocity fluctuations resulting from the trains of vortex rings in the shear layer. The time period $T^{*}$ of the regular oscillation was taken as the characteristic time scale in this region. It is of great importance to examine the unsteadiness of the large-scale turbulent structure responsible for the heat transfer enhancement.

It is well known that coherent structures are usually found intermittently. ${ }^{20)}$ The conventional statistical analysis is blurred by the presence of the background turbulence. Kovasznay et al. ${ }^{14)}$ applied conditional analysis in the investigation of turbulent bulges at the outer edge of a turbulent boundary layer. In the present work, the following statistical analysis with conditional sampling was made to discern strong turbulent flow regimes of impinging round jets:

$I(t)= \begin{cases}1: & \text { if }\left|\frac{d u_{s} v_{s}}{d t}\right| \geq \text { Th.1 and }\left|\frac{d^{2} u_{s} v_{s}}{d t^{2}}\right| \geq \text { Th.2 } \\ & \text { for strong turbulent flow } \\ 0: & \text { otherwise }\end{cases}$

for nonturbulent or weak turbulent flow

In addition to the turbulence intensity, the first and second time-derivatives of the instantaneous Reynolds stress can also be regarded as a measure of the strength of turbulence. The time-dependent Reynolds stresses and their time-derivatives were calculated by sampling two-channel analog signals of the velocity fluctuations $u_{s}$ and $v_{s}$ at intervals of $1 \mathrm{~ms}$. The following time-averaged values for $H / D=6$ at $R e_{o}=30,000$ were adopted to give the threshold values:

$$
\text { Th. } 1=0.7\left|\overline{\frac{d u_{s} v_{s}}{d t}}\right| \quad \text { and } \quad \text { Th. } 2=0.7\left|\overline{\frac{d^{2} u_{s} v_{s}}{d t^{2}}}\right|
$$

for $H / D=6$ and $R e_{o}=30,000$.

The overbar implies the conventional time-averaged values. The numerical coefficient 0.7 was determined as the most appropriate value after the statistical analysis was made, adjusting the numerical coefficient so that $\gamma$ reaches 1 when $H / D=5 \sim 8$ (i.e. the nozzleto-plate spacings for maximal heat transfer). The two threshold values were made constant. It is one of the reasons that the criteria should be rigid for clear-cut judging whether the flow at the measuring point is strongly turbulent or not.

As shown in Fig. 7, the intermittency function $I(t)$ is a random square wave. For small nozzle-to-plate spacings $H / D<4, I(t)$ hardly becomes 1 because the impinging jet still keeps the potential core. On the other hand, $I(t)$ very frequently becomes 1 for large spacings $H / D \geq 5$ because the impinging jet is fully turbulent with large-scale eddies. It has been found that the strong intermittency appearing for $4.5<H / D<6$ is attributable to the quasi-periodic alternate impingement of the strong turbulent and the nonturbulent stream rather than the fast- and slowmoving core fluid. ${ }^{11)}$ For the optimal spacing $H / D=6-8$, only the strong turbulent stream carrying large-scale energy-containing eddies impinges on the stagnation-point boundary layer at high arrival velocity.

Figure 8 shows the intermittency coefficient defined by the following equation:

$$
y=\lim _{t_{o} \rightarrow \infty} \frac{1}{t_{o}} \int_{t}^{t+t_{o}} I(t) d t
$$

It can be seen that $\gamma$ becomes maximal around $H / D=7$ when $R e_{0}>10,000$. When $R e_{0} \leq 10,000$, $\gamma$ remains almost zero because the jet has only weak turbulent streams with so-called coarse turbulence. This does not imply a conflict with the fact that the stagnation-point heat transfer is enhanced even for smaller Reynolds numbers around $H / D=$ 6 because the rigid criteria were adopted for the conditional analysis only.

At the present stage, it is very difficult to analyze the intermittent characteristics of the impingement heat transfer using the intermittency function because the present conditional analysis cannot exclude arbitrariness in determining the threshold values.

It may be considered from the viewpoint of the turbulent surface-renewal concept that the enhancement of heat transfer in impinging jets occurs due to the impingement of large-scale energetic eddies on the thermal boundary layer. That is, the kinetic energy $\sqrt{{\overline{u_{s}}}^{2}}$ and the characteristic impingement frequency $f$ are the dominant parameters of the turbulent surface-renewal. The surface-renewal frequency can be assumed to be the reciprocal of the characteristic time scale:

$$
\begin{array}{lll}
f=1 / T^{*} & \text { for } & H / D \leq 4.5 \\
f=1 / T & \text { for } & H / D>4.5
\end{array}
$$

Figure 9 is the correlation of the Frössling number with the dimensionless surface-renewal parameter. As the parameter goes to zero, the Frössling number approaches the theoretical prediction 0.88 for the 


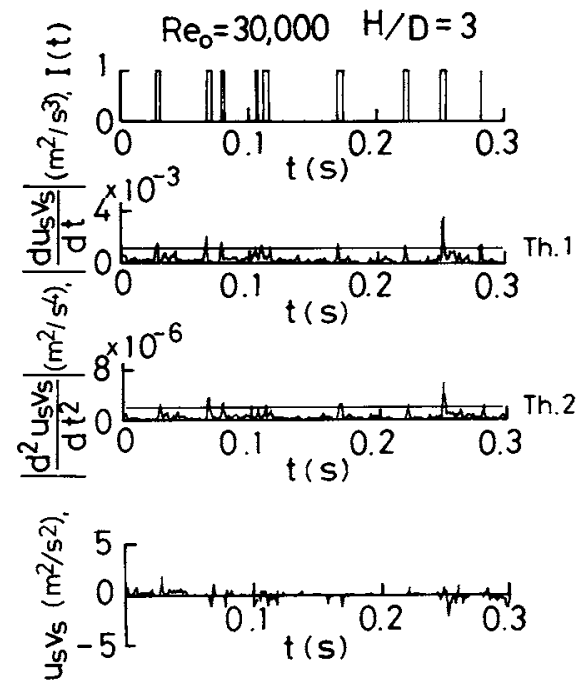

Fig. 7a. Intermittency function obtained by conditional sampling for $H / D=3$.

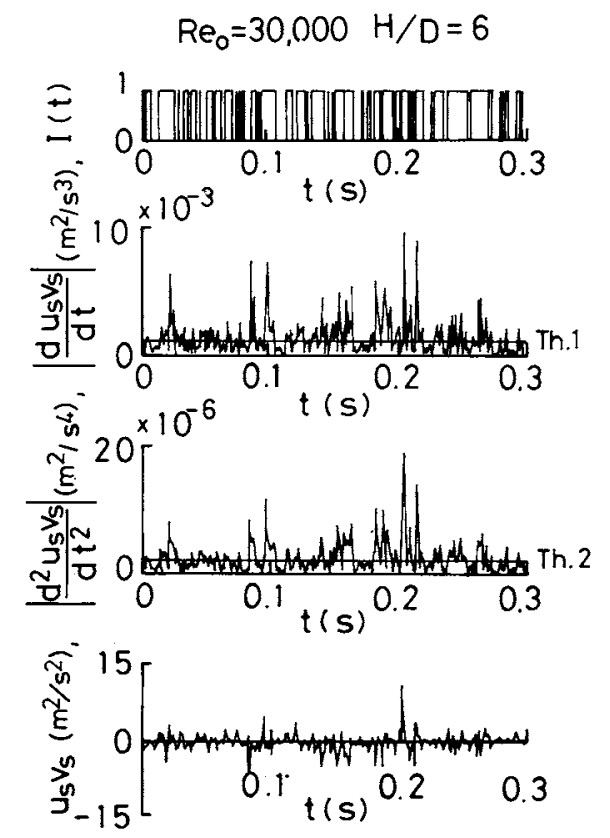

Fig. 7b. Intermittency function obtained by conditional sampling for $H / D=6$.

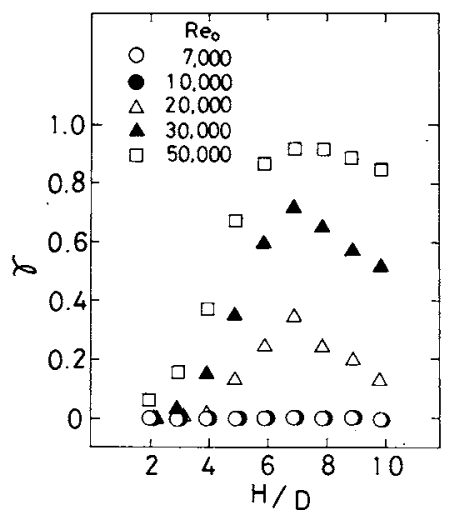

Fig. 8. Intermittency coefficient.

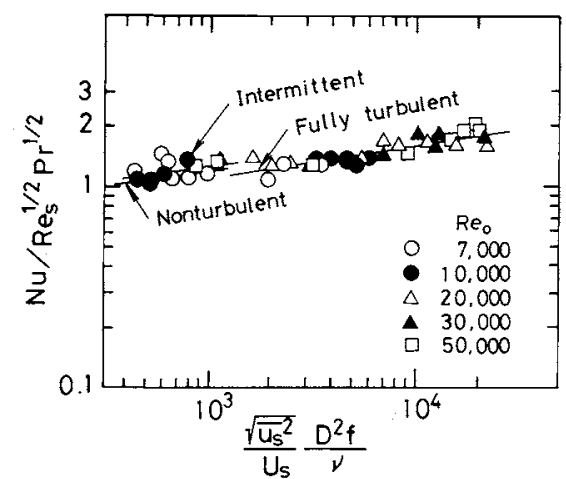

Fig. 9. Correlation of Frössling number with surface renewal parameter.

turbulence-free condition. It can be interpreted that the surface-renewal parameter is the product of the turbulent Reynolds number $\sqrt{{\overline{u_{s}}}^{2} D / v}$ and the Strouhal number $D f / U_{s}$ based on the large-scale eddies impinging on the stagnation-point boundary layer at the arrival velocity.

The best-fit equation based on the velocity and timescale of the fully-turbulent flow regime is given by

$$
\begin{aligned}
& \frac{N u}{\operatorname{Re}_{s}^{1 / 2} \operatorname{Pr}^{1 / 2}}=0.88+2.65 \times 10^{-3}\left(\operatorname{Re}_{t} S t_{t}\right)^{0.637} \\
& 1.5 \times 10^{3}<R e_{t} S t_{t}<2.5 \times 10^{4}
\end{aligned}
$$

It would be possible to draw a single straight line through the scattered data points over the whole range of the surface-renewal parameter in spite of the difference in the definition of time scale between the nonturbulent and intermittent regions and the fullyturbulent region.

\section{Concluding Remarks}

The optimal nozzle-to-plate spacing for maximal stagnation-point heat transfer lies between 5 and 8 nozzle diameters. The holding time fraction of a strong turbulent stream carrying large-scale energycontaining eddies becomes maximal when $H / D=6-8$. The enhancement of heat transfer in the stagnationpoint region is mainly caused by the impingement of the strong turbulent stream. The effect of heat transfer enhancement can be successfully explained by the surface-renewal parameter consisting of the turbulent Reynolds and Strouhal numbers based on the large-scale eddies impinging on the stagnation-point boundary layer.

\section{Acknowledgment}

Financial support provided by the Asahi Glass Foundation for Industrial Technology is gratefully acknowledged.

\section{Nomenclature}

$D \quad=$ nozzle diameter 
$1 / T$ or $1 / T^{*}$

$=$ nozzle-to-plate spacing

$=$ stagnation-point heat transfer coefficient

$=$ intermittency function

$=$ stagnation-point Nusselt number, $h D / \kappa$

$=$ Prandtl number

$=$ autocorrelation function

$=$ Reynolds number, $U D / v$

$=$ turbulent Reynolds number, $\sqrt{\bar{u}_{s}^{2}} D / v$

$=$ radial distance from jet axis

$=$ jet half-radius determined from velocity distribution

$=$ Strouhal number, $D f / U_{s}$

$=$ integral time scale

$=$ time period of periodical core fluctuation

$=$ threshold value defined by Eq. (8)

$=$ threshold value defined by Eq. (8)

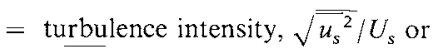
$\sqrt{\overline{u_{m}^{2}}} / U_{m}$

[Hz] $\quad t \quad=$ turbulent

[m] $T F \quad=$ turbulence-free condition

$\left[\mathrm{W} / \mathrm{m}^{2} \mathrm{~K}\right] \quad$ Literature Cited

[-] 1) Chia, C-J., F. Giralt and O. Trass: Ind. Eng. Chem., Fundam. 16, 28 (1977).

2) Donaldson, C. D., R. S. Snedeker and D. P. Margolis: J. Fluid Mech., 45, 477 (1971).

3) Gardon, R.: J. Heat Transfer, C82, 396 (1960).

4) Gardon, R. and J. Cobonpue: Int. Dev. in Heat Transfer, 454, ASME, New York (1963).

5) Giralt, F., C-J. Chia and O. Trass: Ind. Eng. Chem., Fundam., 16, 21 (1977).

6) Gorla, R. S. R. and N. Nemeth: Proc. 7th Int. Heat Transfer Conf., Vol. 3, FC28, pp. 153 (1982).

7) Hoogendoorn, C. J.: Int. J. Heat Mass Transfer, 20, 1333 (1977).

8) Hrycak, P.: Int. J. Heat Mass Transfer, 26, 1857 (1983).

9) Kataoka, K.: Drying Tech., 3, 235 (1985).

10) Kataoka, K.: "Special Flow Techniques in Heat Transfer Augmentation," Rev. Paper, Chem. Eng., Japan, 49, 269 (1985).

$=$ time

$=$ centerline velocity of jet

$=$ axial component of velocity fluctuation (at $r=0$ )

$=$ transverse component of velocity fluctuation (at $r=0$ )

$=$ axial distance from jet exit

$=$ intermittency coefficient

$=$ turbulence correction factor

$=$ thermal conductivity

$=$ integral length scale

= kinematic viscosity

$=$ time difference

$\left[\mathrm{m}^{2} / \mathrm{s}\right]$

[s]

[s]

$[\mathrm{m} / \mathrm{s}]$

$[\mathrm{m} / \mathrm{s}]$

$[\mathrm{m} / \mathrm{s}]$

$[\mathrm{m}]$

$[-]$

$\mathrm{K}]$

]

$\tau$

〈Superscript〉

$=$ time-averaged

〈Subscripts〉

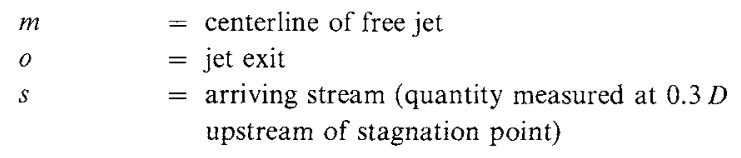

11) Kataoka, K., I. Mihata, K. Maruo, M. Suguro and T. Chigusa: Proc. 8th Int. Heat Transfer Conf., to be published.

12) Kataoka, K., M. Suguro, H. Degawa, K. Maruo and I. Mihata: Int. J. Heat Mass Transfer, to be published.

13) Kataoka, K., Y. Kamiyama, S. Hashimoto and T. Komai: $J$. Fluid Mech., 119, 91 (1982).

14) Kovasznay, L. S. G., V. Kibens and R. F. Blackwelder: $J$. Fluid Mech., 41, 283 (1970).

15) Lowery, G. W. and R. I. Vachon: Int. J. Heat Mass Transfer, 18, 1229 (1975).

16) Nakatogawa, T., N. Nishiwaki, M. Hirata and K. Torii: Proc. 4th Int. Heat Transfer Conf., FC5.2 (1970).

17) Popiel, C. O., T. H. van der Meer and C. J. Hoogendoorn: Int. J. Heat Mass Transfer, 23, 1055 (1980).

18) Schon, J. P. and G. Charnay: "Measurement of Unsteady Fluid Dynamic Phenomena," ed. by B. E. Richards, Hemisphere, Chap. 12, 291 (1977).

19) Yokobori, S., N. Kasagi, M. Hirata and N. Nishiwaki: Proc. 6th Int. Heat Transfer Conf., Vol. 5, pp. 305 (1978).

20) Zaric, Z.: "Turbulent Forced Convection in Channels and Bundles," ed. by S. Kakac and D. B. Spalding, Hemisphere, Vol. 1, pp. 403 (1979). 